
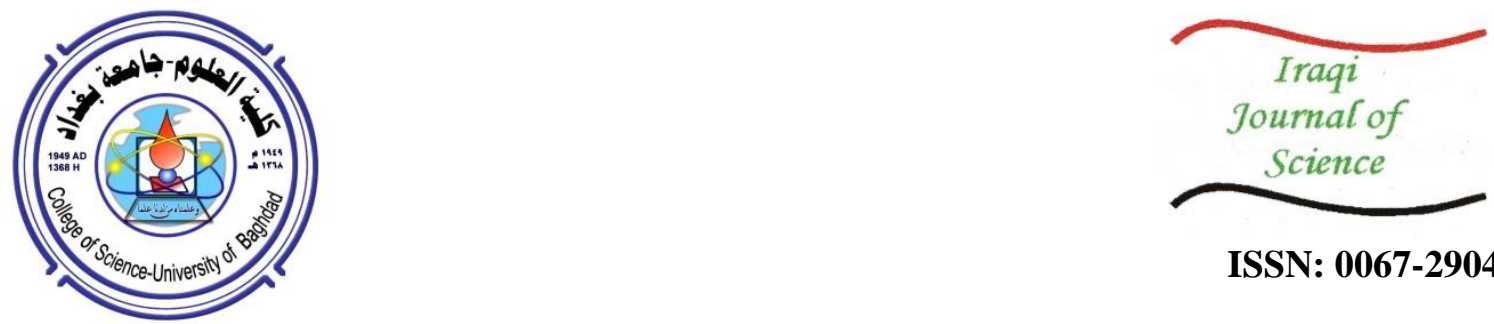

ISSN: 0067-2904

\title{
The Utilization of Remote Sensing Imagery and Inverse Distance Weighted Scheme to Simulate the White Oil Effects on Soil Geotechnical Properties
}

\author{
H. W. Abdulwadud ${ }^{1 *}$, L. A. Jawad ${ }^{2}$, Z. A. Hameed ${ }^{1}$ \\ ${ }^{1}$ Department of remote sensing and geographic information system, College of Science, University of Baghdad, \\ Iraq \\ ${ }^{2}$ Remote Sensing Unit, College of Science, University of Baghdad, Iraq
}

Received: 12/2/2020 Accepted: 9/12/2020

\begin{abstract}
This research aims to utilize a complementarity of field excavations and laboratory works with spatial analyses techniques for a highly accurate modeling of soil geotechniques properties (i.e. having lower root mean square error value for the spatial interpolation). This was conducted, for a specified area of interest, firstly by adopting spatially sufficient and well distributed samples (cores). Then, in the second step, a simulation is performed for the variations in properties when soil is contaminated with commonly used industrial material, which is white oil in our case. Cohesive (disturbed and undisturbed) soil samples were obtained from three various locations inside Baghdad University campus in AL-Jadiriya section of Baghdad, Iraq. The unified soil categorization system (USCS) was adopted and soil was categorized as clayey silt of low plasticity (CL). The cores were contaminated in a synthetically manner using two specified values of white oil (5 and $10 \%$ of its dry weight). Then, the samples were left for three days to certify homogeneity. The results of laboratory tests were enhanced by spatial interpolation mapping, using Inverse Distance Weighted scheme for normal soil samples and those with synthetic pollution. The liquid limit rates were raised slightly as contamination rates raised, while particle size was reduced; in contrary, shear strength parameter values were decreased.
\end{abstract}

Keywords: high resolution images, soil mechanical characteristics, soil physical characteristics, and spatial interpolation

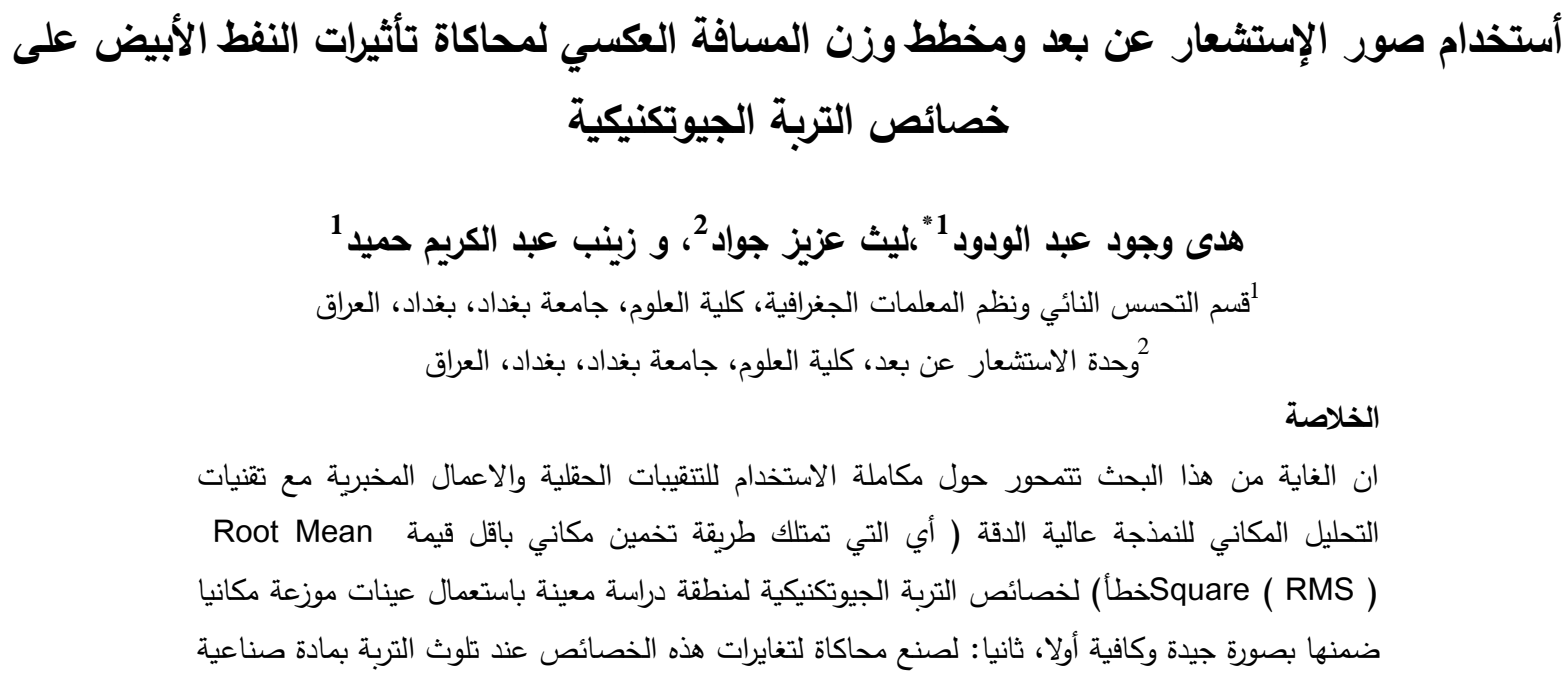

*Email: laithazeez@scbaghdad.edu.iq 


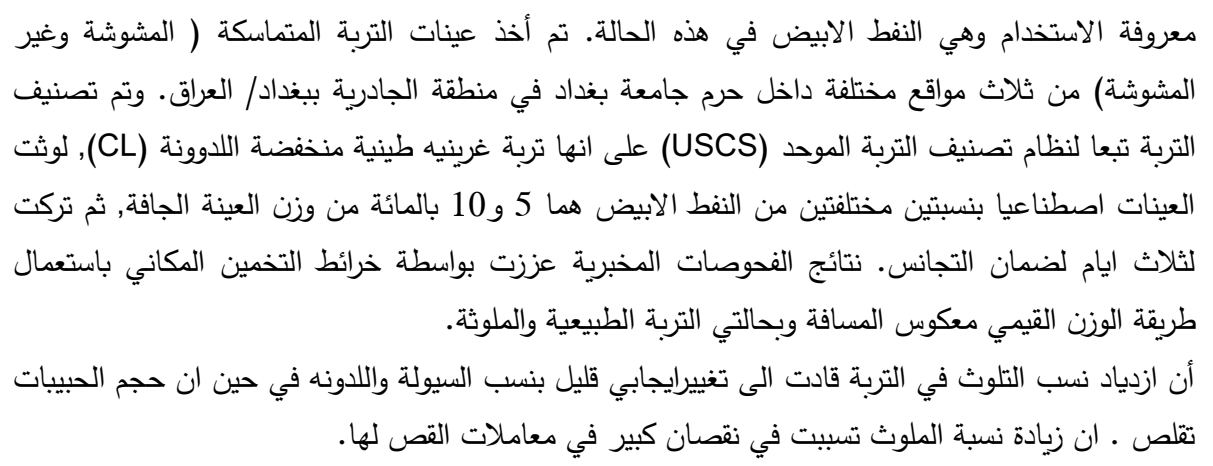

\section{Introduction}

The increment of the extension of urbanized areas and the ascent in the number of industrial facilities yielded an increment in the levels of many chemical (solid or liquid) wastes that percolate into soil. These activities resulted (intentionally or unintentionally) in environmental pollution [1]. The percolation of contaminated wastes to the underground affects not only groundwater quality, which sometimes changes its utilization direction (domestic, agricultural, or industrial ) (2), but also some soil geotechnical characteristics (if wastes contamination exceeds specified limits), such as soil bearing capacity or soil settlement value [3, 4]. Common contaminating wastes include liquid hydrocarbon, pesticides, heavy meatals, fertilizers, and volatile organics. The sources of organic pollutants include oil-production fields, electricity stations that use thermal energy, and accidental spilling of oil as a result of leaking from oil pipelines or fixed and/ or mobile storing tanks [2].

Some parameters of soil determine contaminated wastewater flow in it or in the groundwater's main soil. These include, for example, permeability, porosity, and adsorption. The most affected type of soil is the clayey soil, since it is electro-chemically active [5]. The chemical composition of the contaminated material, in addition to soil properties, determines contamination extension [6].

1. Soil's engineering characteristics are influenced differently when the soil is contaminated [2]. Clayey soil cementing and shear strength parameter would be decreased [7]. Liquid limit (LL) would be decreased, yielding plasticity index (PI) decrement and plastic limit (PL) increment [8]. Internal friction angle $(\varphi)$ would be reduced [9]. Various types of deformation of solid skeleton occur, which alters soil settlement and compressibility. Properties that are affected include pore pressure, saturation degree, pore liquid, which is commonly called osmotic suction, and chemical composition [10]. Voids could be filled with fines [11]. Increment in voids ratio of the soil can occur, which raises consolidation coefficient (cv) [12]. Within the compaction process, varying water content and maximum dry density values can be observed $[1,13]$.

2. Many GIS environment softwares are capable of building high resolution digital models that is easy to use and demonstrate soil natural or normal phenomena, since those specialized programs have the ability to integrate effective factors surrounding the soil [14, 15]. The GIS models of soil are categorized into two classes; the first consists of accurate multilayers maps of water resources, ecological factors, remotely sensed extracted data, field survey data, soil investigation reports, and lab analyzing results. While the second class of models consists of spatial interpolation raster or vector images The diagram below demonstrates this role. 


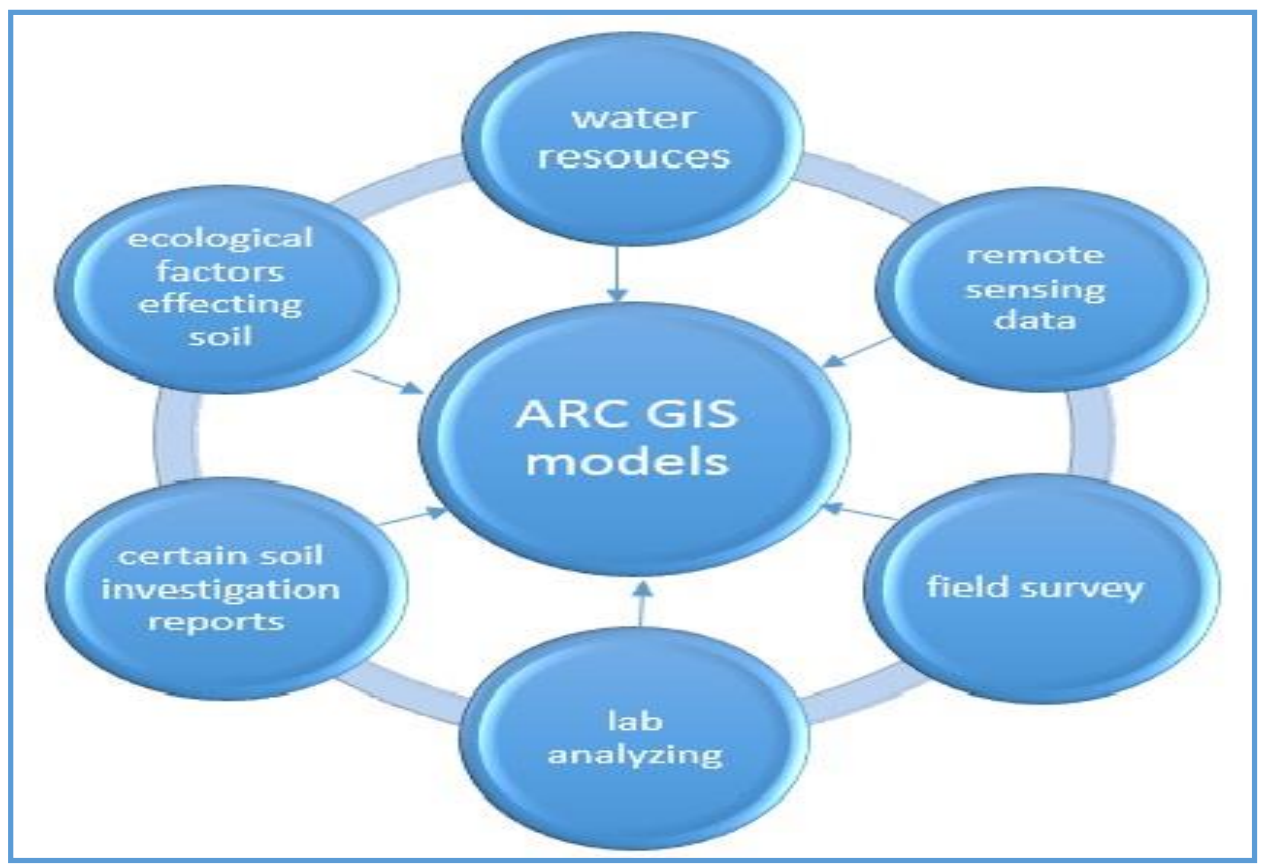

Figure 1- Illustrative diagram of GIS role in soil models.

\section{Materials and Methods}

\section{- Study Area}

The region of interest, from where the disturbed and undisturbed soil cores were obtained, is located in Baghdad University campus at AL-Jadiriya district in Baghdad, Iraq. It extends between the $44.371^{\circ}$ to $44.389^{\circ}$ eastern longitudes and $33.264^{\circ}$ to $33.282^{\circ}$ northern latitudes, covering 2.248 square kilometers. The region's exact borders were delineated using high spatial resolution satellite imagery (Sentinel-2a imagery with $10 \mathrm{~m}$ pixel resolution), as shown in Figure-2. Three arbitrary pits were excavated to one meter under the apparent surface level, utilizing handle Excavator. Two soil core classes were acquired from each arbitrary hole (disturbed and undisturbed) of soil cores. As for disturbed cores, they were used for measuring the effects of the contamination material on the physical and mechanical characteristics, while the undisturbed soil cores were used for measuring unit weight of the field and moistur content. Those cores were placed in airtight containers with essential data labels. After that, they were hauled to soil mechanics laboratory. Based on ASTM-D2937( 18 $\mathrm{kN} / \mathrm{m}^{3}$ for L1 , $19 \mathrm{kN} / \mathrm{m}^{3}$ for L2 and $26 \mathrm{kN} / \mathrm{m}^{3}$ for L3), the readings of unit weight of the field and moisture content were calculated. The results showed values of $21 \% 23 \%$, and $20 \%$ for L1, L2, and L3, respectively. Each core was contaminated with two percentage values (5 and 10) \% of wollastonite (WO) of dry weight of soilcore in the lab. Hand mixing scheme was utilized, then the mixed cores left for three days to allow chemical reactions between soil mineral compositions and oil .

L1 denotes the location of sample extraction in the site of the Engineering College $\left(44.375^{\circ} \mathrm{E}\right.$ and $\left.33.272^{\circ} \mathrm{N}\right)$.

L2 denotes the location of sample extraction in the site of the Science College (44.381 ${ }^{\circ} \mathrm{E}$ and $33.275^{\circ}$ $\mathrm{N})$.

L3 denotes the location of sample extraction in the site of the Agriculture College $\left(44.378^{\circ} \mathrm{E}\right.$ and $\left.33.271^{\circ} \mathrm{N}\right)$. 


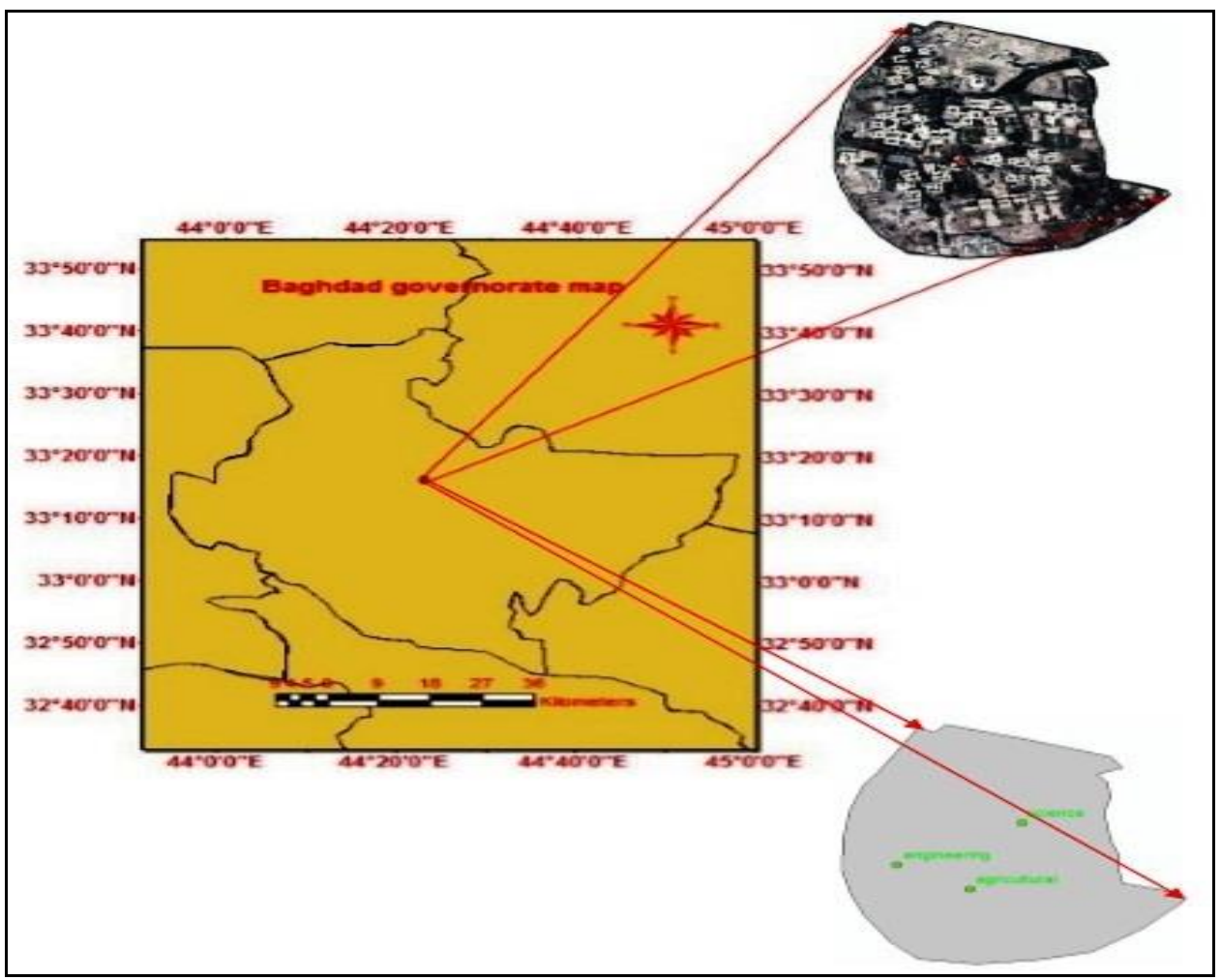

Figure2- Study area at Baghdad University campus at AL-Jadiriya district in Baghdad province

Lab testing was conducted on soil samples in both cases (distributed and non- distributed) before and three days after contamination. In the beginning, the disturbed soil samples were mixed with the two percentages of the contaminant (5 and $10 \%$ dry weight). Then, according to density of field and natural moisture content, they were molded for testing. Soil samples were categorized as intact soil (WO0), 2.5\% contaminated soil (WO1), and 3.10\% contaminated soil (WO2).

liquid and plastic limits (D4318), specific gravity (D854), and particle size distribution (D422) of soil were mesured as the physical properties, while the Unconfined Compressive Strength Test (UCST) (D2166) was the mechanical test applied on remolded soil samples (intact and contaminated), which was achieved successively according to the American Society for Testing Materials (ASTM).

\section{Results and Discussion}

\section{- Physical characteristics of soil}

The utilized equations employed to calculate the values of physical properties were:

Water or moisture content $\mathrm{w}=\frac{M w}{M d} \mathrm{x} 100(\%) \ldots . .(1)$,

where $M_{w}$ is mass of water and $M_{d}$ is dry mass of soil sample.

The sieve analysis (or gradation test) is a procedure that is commonly used in civil engineering to assess the particle size distribution (also called gradation) of a granular material by allowing the material to pass through a series of sieves of progressively smaller mesh size and weighing the amount of material that is stopped by each sieve as a fraction of the whole mass.

Sieve analysis has, in general, been used for decades to monitor material quality based on particle size. For coarse materials, with sizes that range down to 100 mesh $(150 \mu \mathrm{m})$, the sieve analysis and particle size distribution are accurate and consistent.

However, for a material that is finer than 100 mesh, dry sieving can be significantly less accurate. This is because of the mechanical energy required to make particles pass through an opening as well as the fact that the surface attraction effects between the particles themselves and between particles and the screen increase as the particle size decreases. Wet sieve analysis can be utilized where the material 
analyzed is not affected by the liquid, except to disperse it. Suspending the particles in a suitable liquid transports fine material through the sieve is much more efficient than shaking the dry material.

Sieve analysis assumes that all particles will be round (spherical) or nearly so and will pass through the square openings when the particle diameter is less than the size of the square opening in the screen. For elongated and flat particles, a sieve analysis will not yield reliable mass-based results, as the particle size reported will assume that the particles are spherical, where in fact an elongated particle might pass through the screen end-on, but would be prevented from doing so if it presented itself sideon.

Percentage values of the contents of of silt, clay, and copper (uniformity coefficient) were obtained from the grain-size distribution curve (sieve analysis test), as shown in Figure-3, where :

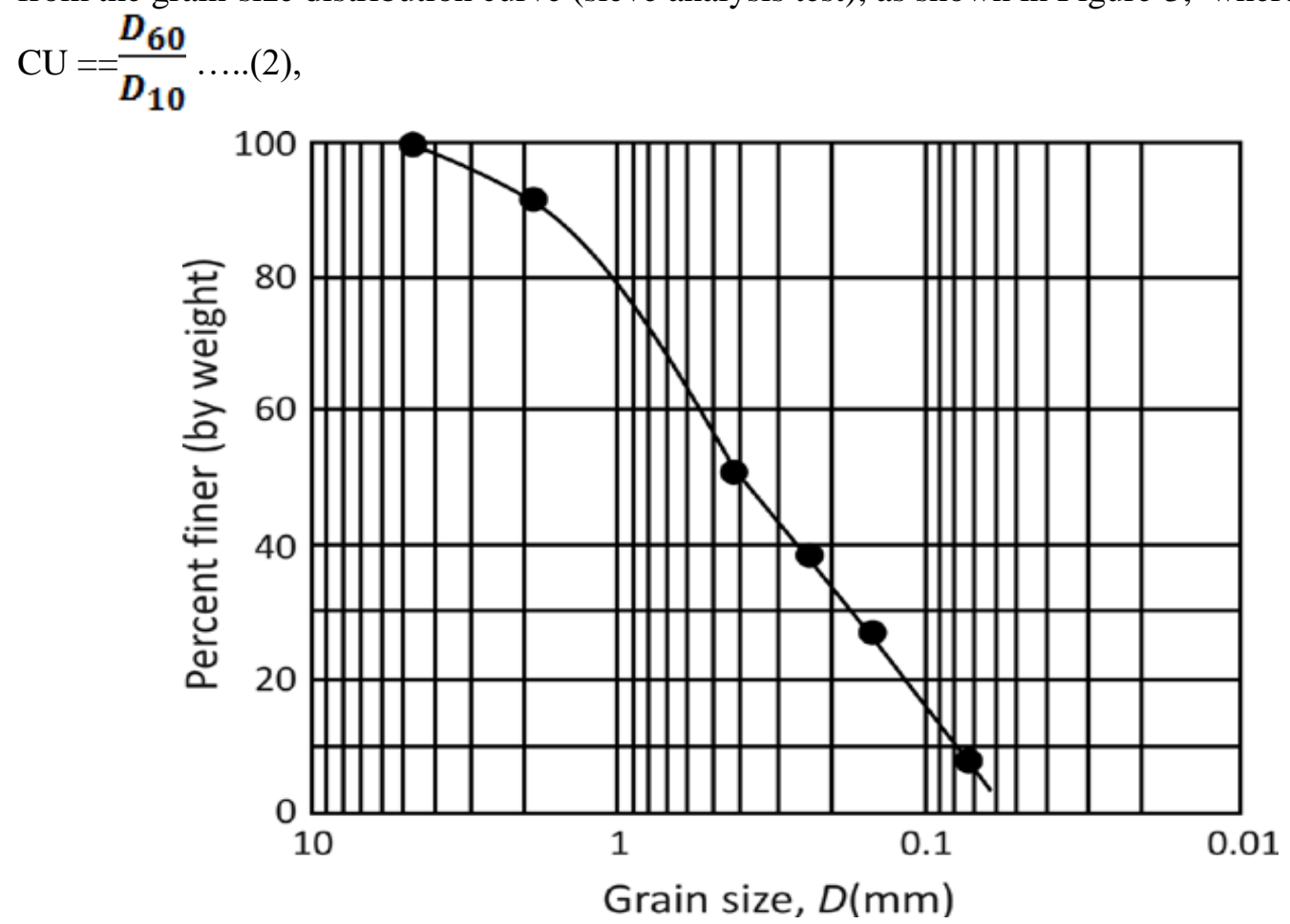

Figure 3- Grain-size distribution curve of coarse grained soil as obtained from sieve analysis.

Where $D_{10}$ and $D_{60}$ are the diameters corresponding to the percentage values of fines (10 and $\left.60 \%\right)$, respectively.

3. Liquid limit (L.L) (Casagrande method) and plastic limit (P.L) were obtained from Atterberg Limits Tests. Plasticity Index (P.I) was calculated as P.I= L.L - P.L. Specific gravity of soils (Gs) was calculated according to the following equation:

$\mathrm{G}_{\mathrm{S}}=\frac{W_{s / V_{B}}}{\gamma_{W}}$

where $\mathrm{W}_{\mathrm{s}}$ is weight of soil solid, $\mathrm{V}_{\mathrm{s}}$ is volume of soil solid, and $\gamma_{\mathrm{w}}$ is density of water.

A summary of physical properties of soil sampls tested in this work is given in table (1).

Table 1- Physical characteristics of soil cores before and after contamination

\begin{tabular}{|ccccccccccc|}
\hline & \multicolumn{4}{c}{ engineering college } & \multicolumn{3}{c|}{ science college } & \multicolumn{3}{c|}{ agriculture college } \\
characteristics & WO $_{0}$ & WO $_{1}$ & WO $_{2}$ & WO $_{0}$ & WO $_{1}$ & WO $_{2}$ & WO $_{0}$ & WO $_{1}$ & WO $_{2}$ \\
G.S & 2.68 & 2.66 & 2.53 & 2.66 & 2.56 & 2.66 & 2.69 & 2.69 & 2.66 \\
Silt & $\mathbf{7 4 . 8 9 \%}$ & $\mathbf{7 4 . 8 9}$ & 77 & 76 & 76 & 78 & 73 & 73 & 72 \\
Clay & $18 \%$ & 18 & 13 & 18 & 18 & 13 & 20 & 20 & 17 \\
L.L & 26 & 22 & 20 & 30 & 26 & 22 & 40 & 39 & 34 \\
P.I & 26 & 30 & 34 & 14 & 18 & 20 & 29 & 33 & 35 \\
\hline
\end{tabular}


The achieved results refer to some points. Raising the percentage of contaminant causes a remarked decrement in specific gravity rates due to the low density of WO, while this raising in the percentage of WO leads to a slight decrement in the fine particles rate because of soil clods construction. Also, the hydrometer test proves that all salt kinds which covered the particles of soil were dissolved in water. This process is relative to solubility of existing salts in water, as shown in Figure-4.

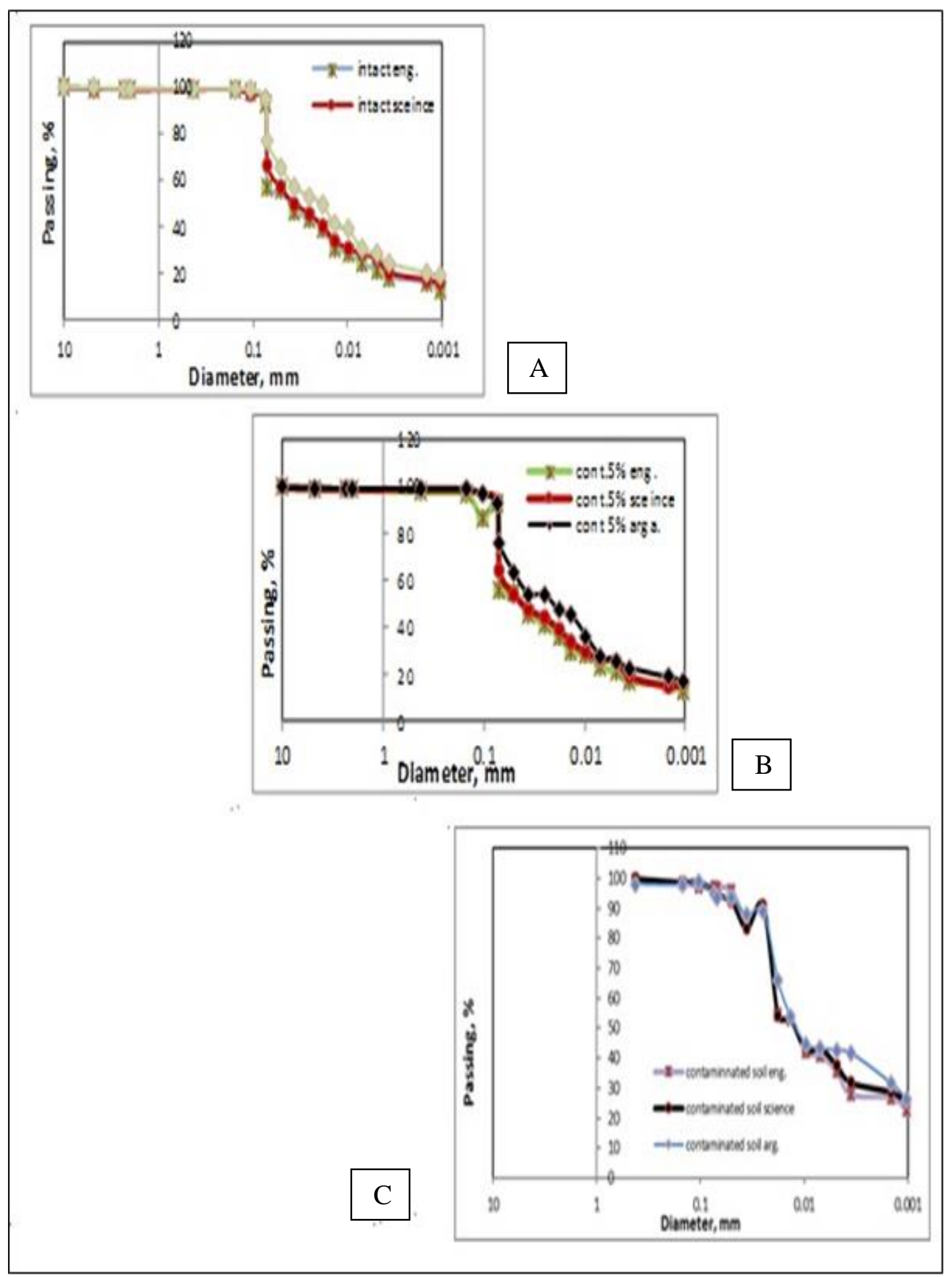

Figure 3- The effects of WO on soil's salt solubility for different grain diameters at: A) zero contamination B) $5 \%$ contamination C) $10 \%$ contamination.

The liquid limit rates increased with increasing the percentage of contaminant, due to solid particle's surface coating by white oil molecules. White oil results in ascending the plasticity of soil due to the viscosity of such waste material which occurs due to the immiscibility of petroleum 
materials with water. These materials make contact with soil particles and not with water, so that contaminated soil acts like a fluid or plastic medium in the presence of water. This activity was lessening when raising the WO percentage; therefore, liquid limit value was reduced whereas plastic limit rates were increased. Using these experimental values as a geographically referenced information (i.e. point shapefile with attribute table), a distinctive spatial interpolation method (Inverse Distance Weighted) was adopted to model physical properties of clean soil for the whole university campus and simulate their changes with the change in the content of contaminated soil. . Inverse distance weighted is a deterministic spatial interpolation approach to estimate an unknown value at a location using some known values with corresponding weighted values. The basic formula is as follows:

where $\mathbf{x}^{*}$ is an unknown value at a location to be determined, $\mathrm{w}$ is the weight, and $\mathrm{x}$ is a known point value. The weight is the inverse distance of a point to each known point value that is used in the calculation. Simply, the weight can be calculated using the following equation [8].

$$
x^{*}=\frac{w_{1} x_{1}+w_{2} x_{2}+w_{3} x_{3}+\ldots+w_{n} x_{n}}{w_{1}+w_{2}+w_{3}+\ldots+w_{n}}
$$

as shown in Figures- (4), (5), (6), (7), and (8).

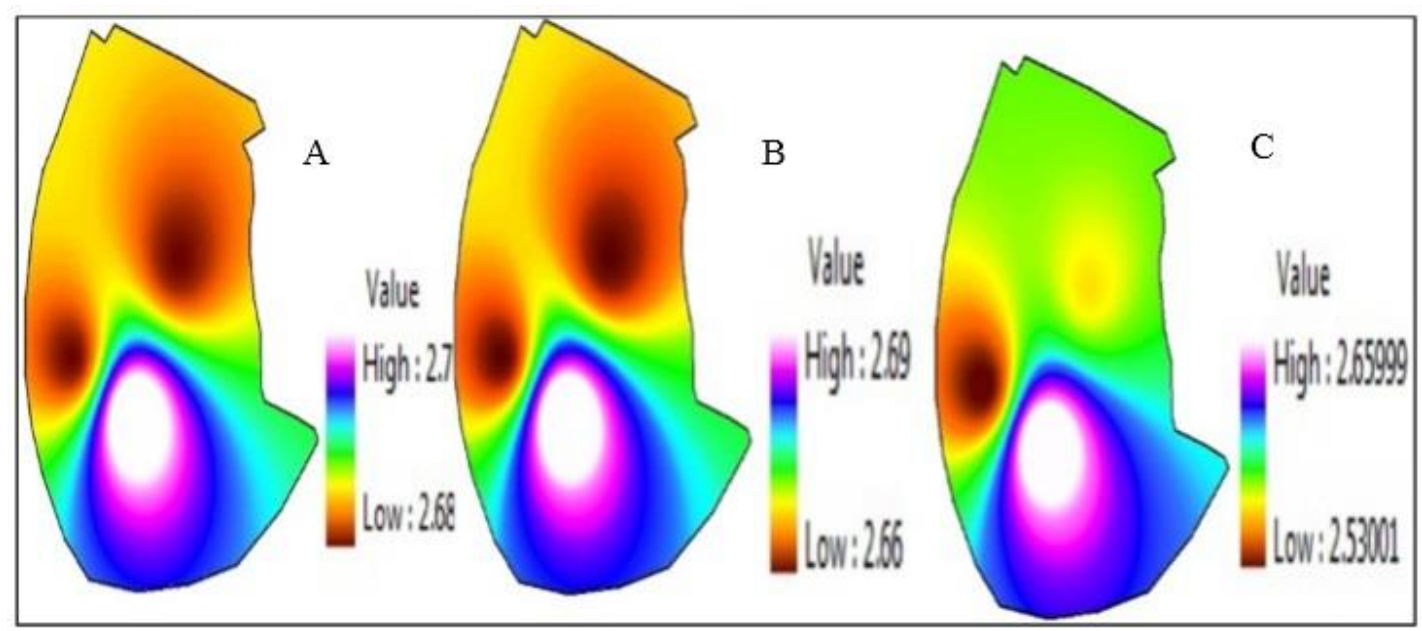

Figure 4- Baghdad University campus specific gravity measurements for A. intact soil, B. 5\% contaminated soil, and C. $10 \%$ contaminated soil.

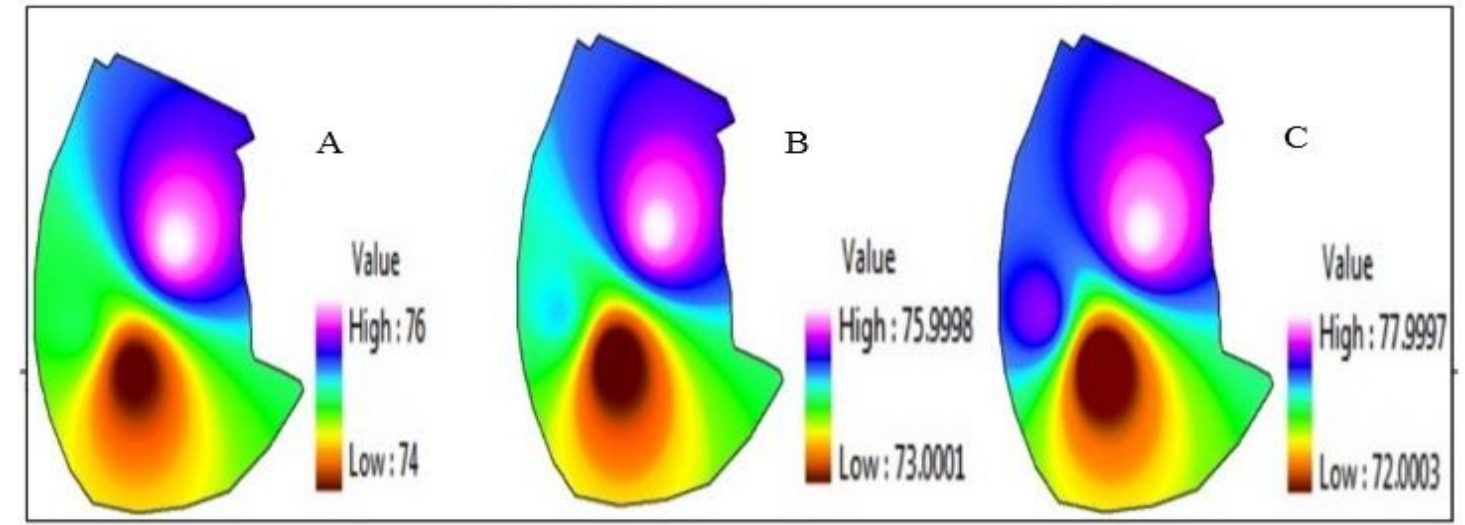

Figure 5- Baghdad University campus silt content for A. intact soil, B. 5\% contaminated soil, and C. $10 \%$ contaminated soil. 


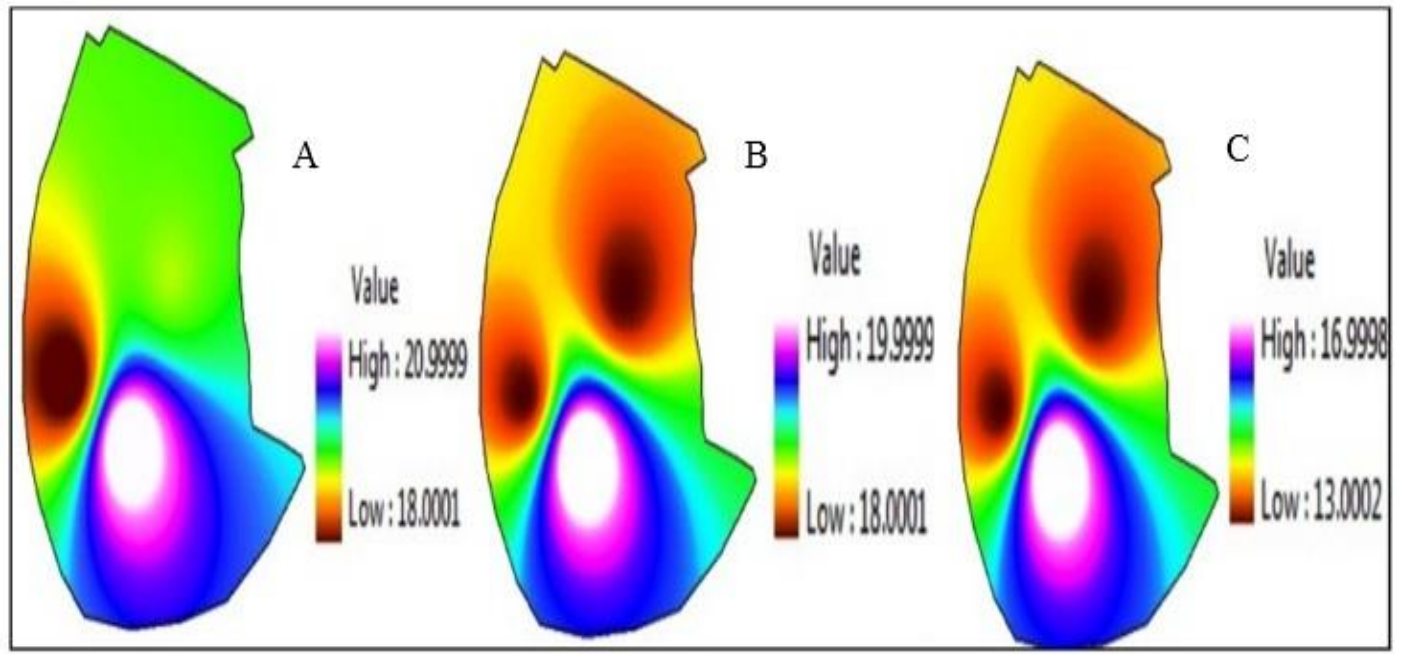

Figure 6- Baghdad University campus clay content for A. intact soil, B. 5\% contaminated soil, and C. $10 \%$ contaminated soil

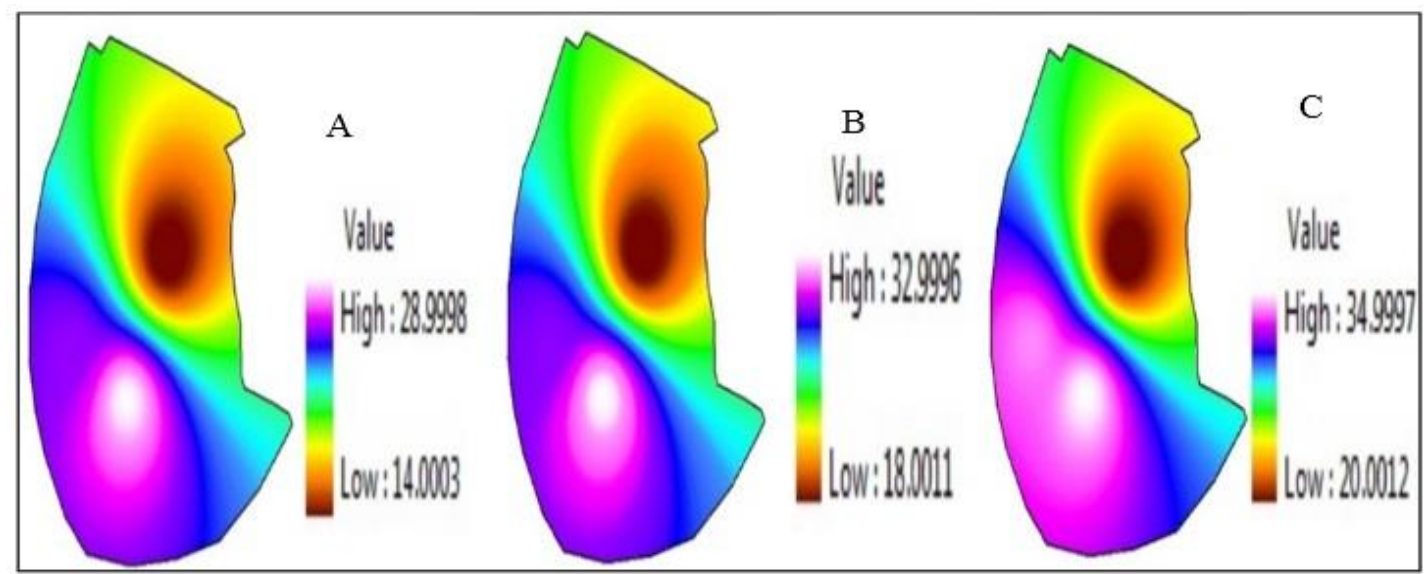

Figure 7- Baghdad University campus liquid limits for A. intact soil, B. 5\% contaminated soil, and C. $10 \%$ contaminated soil.

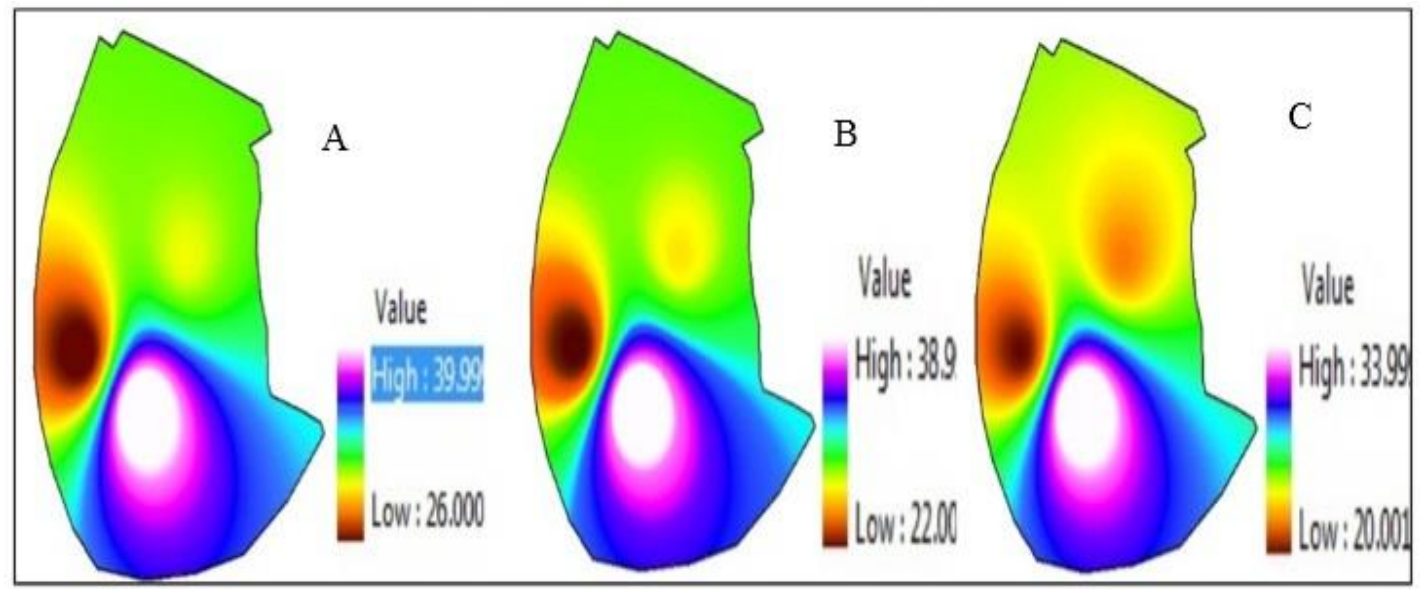

Figure 8- Baghdad University campus plastic limits for A. intact soil, B. 5\% contaminated soil, and C. $10 \%$ contaminated soil.

\section{-Soil mechanical characteristics}


Table 2- Mechanical characteristics of soil cores before and after contamination

\begin{tabular}{|cccc|}
\hline Soil Sample & \multicolumn{3}{c|}{$\mathrm{c}_{\mathrm{u}}\left(\mathbf{k N} / \mathbf{m}^{2}\right)$} \\
engineering college & science college & agriculture college \\
$\mathrm{FO}_{0}$ & 36 & 34 & 37 \\
$\mathrm{FO}_{1}$ & 32 & 32 & 34 \\
$\mathrm{FO}_{2}$ & 29 & 30 & 31 \\
\hline
\end{tabular}

The archived results of soil cores presented in table 2 showed a major contamination influence on shear strength parameters. According to the unconfined compressive strength resulted values, there is a reduction in the concentration of copper in the contaminated soil samples WO1 and WO2, which ranged between $80.5 \%$ and $93 \%$ compared with the value in the normal soil sample. This decrement could be yielded by weak bonding in the soil matrix. This weakness happened due to the mixing of the contaminant with the soil. The lubrication property of the contaminant causes soil grains sliding over each other. Hence, it took short-time period for failure. These results are in agreement with those obtained by Karkush and others (1), and Khamehchiyan and others (2). They cited that there is a reduction in the value of copper for the contaminated soils. Also, another study a (16) found reverse relation between qu calculated from UCS and the crude oil content in CL and SM soil samples. The existence of monovalent cations inside pores of water results in a reduction in unconfined compressive strength values, which causes weakness in the soil matrix (5). Using these geographically referenced point results, the IDW method was utilized to model the mechanical properties of clean (normal) soil for the whole university campus and simulate their changes in the soil contaminated with two percentages of WO for the same area, as shown in Figure-9.

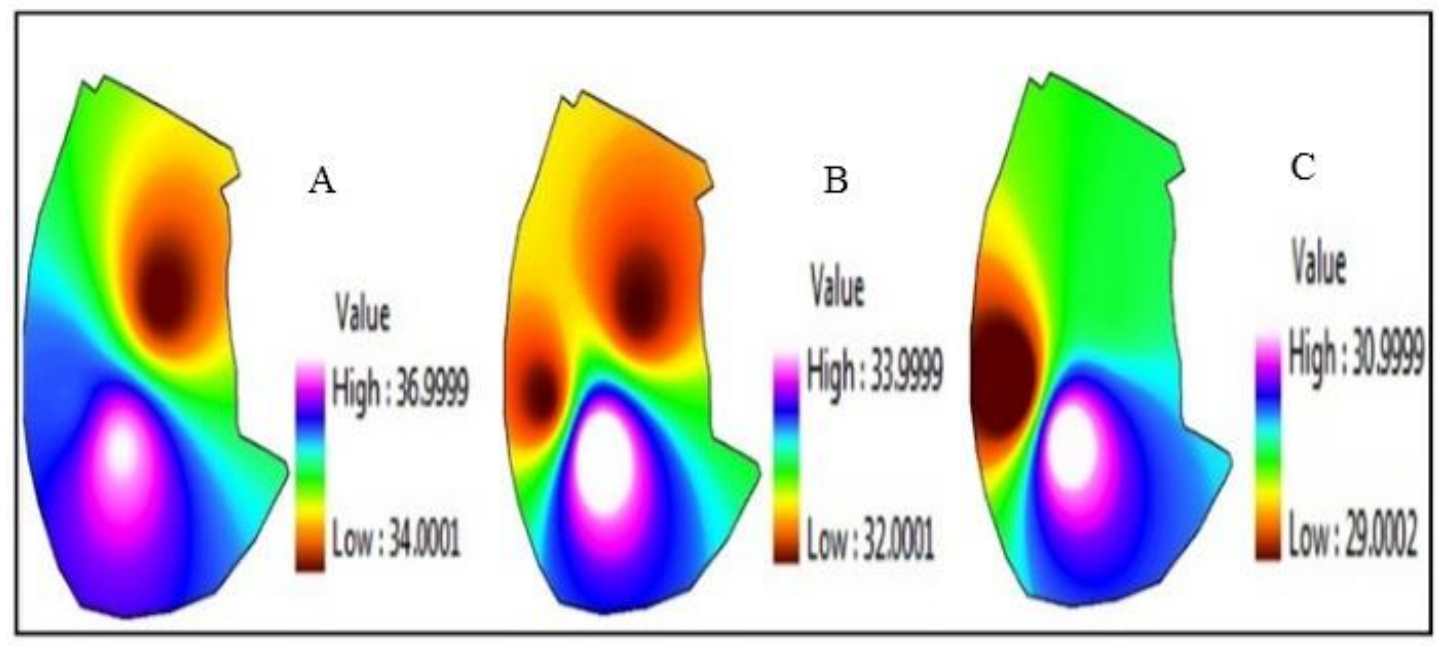

Figure9- Baghdad University campus copper concentrations for A. intact soil, B. 5\% contaminated soil, and C. $10 \%$ contaminated soil.

\section{Conclusions}

The white oil affected negatively the geotechnical characteristics of clayey soil. These affects were increased upon the increase in the soil percentage content of WO. In this work, several experimental results were observed.

The decrement in soil specific gravity rate yielded a small decrement in liquid limit that affected in a negative manner the geotechnical characteristics of clayey soil .

The decrement in soil specific gravity rate also yielded a small increment in plastic limit, which influenced in a negative manner the geotechnical characteristics of clayey soil.

The decrement in soil specific gravity rate yielded a small decrement in the percentage of finer in soil particles, making soil particles coarser than those of normal soil. It is easier to start the test with an oven-dried sample. However, some soils, particularly those with high organic content, are difficult to 
rewet. Hence, they should be tested at their natural water content and determine the oven-dried weight at the end of the test.

-WO influences on shear strength parameters are dependent on WO concentration in soil and test type. The contaminated soil samples showed a reduction in the magnitudes of copper, which ranged between $80.5 \%$ and $93 \%$, as compared to the value in the normal soil sample.

Also, this work revealed that the integrative utilization of field investigations, laboratory tests, and spatial techniques is an optimal approach for achieving experimental results from modeling and simulation, specially when each sample demands many laboratory tests and generate lots of results (i.e. when the field samples are not too many but have a well distribution across the region of interest).

\section{References}

1. Karkush, M. O., and, M. S. Abdul Kareem. 2016. Behavior of pile group subjected to cyclic lateral loading in contaminated soils. International Journal of Geomate.10(2): 1943-1949

2. Khamehchiyan, M., A. M. Charkhabi, and M. Tajik. 2007. Effects of crude oil contamination on geotechnical properties of clayey and sandy soils. Engineering Geology. 89: 220-229.

3. ASTM. 2003. Annual Book of Standards-Soil and Rock; Building; Stone, Peats, John Wiley \& Sons, pp:43-65.

4. Bala, A. K., Q. H. Bari, and A. Ahsan. 2015. Chemical characteristics of native soil in Shrimp Gher and agricultural land. Engineering Journal. 20(2): 1-15.

5. Elisha, A. T.. 2012. Effect of crude oil contamination on the geotechnical properties of soft clay soils of Niger delta region of Nigeria. Electronic Journal of Geotechnical Engineering. 17(1): 1929-1938.

6. Fine, P., E. R. Graber, and B. Yaron. 1997. Soil interactions with petroleum hydrocarbons: abiotic processes. Soil Technology journal, 10: 133-153.

7. George, S. E., A. Sabu, and, M. George. 2015. Effect of diesel oil on the geotechnical properties of soil. International Journal of Civil and Structural Engineering Research. 2(2): 113-117.

8. Gratchev, I. B., and I. Towhata. 2009. Effect of acidic contamination on the geotechnical properties of marine soils in Japan. University of Tokyo. proceeding of $19^{\text {th }}$ international offshore and polar engineering conference. pp: 21-26.

9. Head, K. M. 1994. Manual of soil laboratory testing. John Wiley \& Sons, Inc., Hoboken, New Jersey, 2nd edition, volume II. pp: 112-124

10. Head, K. M. 2006. Manual of soil laboratory testing. Whittles publishing, Scotland, UK, 3rd edition, volume I. pp: 34-54.

11. Karkush, M. O, A. T. Zaboon, and, H. M. Hussien. 2013. Studying the Effects of Contamination on the Geotechnical Properties of Clayey Soil. Coupled Phenomena in Environmental Geotechnics. Taylor \& Francis Group, London. pp: 599-607.

12. Kermani, M., and T. Ebadi. 2012. The effect of oil contamination on the geotechnical properties of fine-grained soils. soil and sediment contamination: an international journal. 21(5): 655-671.

13. Muhaimeed, A.S., A. Ibrahim, and R. K. Abdulateef. 2017. Using of remote sensing for monitoring geomorphological temporal for changes for Tigris river in Baghdad city. Iraqi Journal of Agricultural Sciences. 48(1): 215-221

14. Jawad, L.A., 2019. Utilizing integration of some remotely sensed morphometric aspects and hypsometric analyses to determine the geomorphological characteristics of AL-Abeadh valley watershade. Iraqi Journal of Agricultural Sciences, 50(1):201-222.

15. Jawad, L.A., F.H. Mahmood, and A.H. Harif. 2019. Determination of optimum dam location in AL-Abeadh basin utilizing remote sensing and geographical information system techniques. Iraqi Journal of Agricultural Sciences, 50 (Special Issue ):222- 232. 